\title{
Coulometric Titration of Urea with Electrogenerated Hypobromite
}

\author{
Jun Kato,*,** Takuma KoseKI,* Yukie AoKI,* Ayako YAMAdA,* and Tatsuhiko TANAKA *广 \\ *Faculty of Engineering, Tokyo University of Science, 1-3 Kagurazaka, Shinjuku, Tokyo 162-8601, Japan \\ **Nuclear Cycle Backend Directorate, Japan Atomic Energy Agency, 4-33 Muramatsu, Tokai, Naka, \\ Ibaraki 319-1195, Japan
}

\begin{abstract}
A definitive method is described for the indirect assay of several tens of milligrams of urea by coulometric titration. Urea was decomposed in concentrated sulfuric acid using a Kjeldahl flask. Subsequently, the formed ammonium ion was titrated with electrogenerated hypobromite ion in a sodium bromide-sodium tetraborate medium of $\mathrm{pH}$ 8.6, with amperometric end-point detection. Parameters affecting the pretreatment procedure were evaluated. The optimized conditions included the heating of $2 \mathrm{~g}$ of urea at around $300^{\circ} \mathrm{C}$ for $2 \mathrm{~h}$ with $10 \mathrm{~cm}^{3}$ of sulfuric acid. Under the proposed conditions, the assay value with expanded uncertainty $(k=2), 99.870 \pm 0.026 \%$, agreed well with the certified value of NIST SRM 912a urea, $99.9 \pm 0.1 \%$.
\end{abstract}

Keywords Coulometric titration, urea, electrogenerated hypobromite

(Received March 25, 2013; Accepted May 2, 2013; Published July 10, 2013)

\section{Introduction}

The simple and reliable determination of urea is one of the subjects of significant research in clinical chemistry. The purity of urea for use as a standard in clinical assay is determined by differential scanning calorimetry (DSC), ${ }^{1}$ such as for the production of National Institute of Standards and Technology (NIST) SRM 912a urea. $^{2}$ With DSC, it is actually impossible to determine the purity directly. The purity of the SRM is accordingly estimated from total impurities, and it is necessary to determine the impurities using other methods. In addition, the purity of analytical reagent-grade urea is conventionally determined by neutralization back titration. ${ }^{3}$ However, a more accurate method is desired to estimate the purity of urea.

Coulometric titration, ${ }^{4-10}$ based on measurements of electric current, time and mass, is a definitive method of chemical analysis because analytical results are directly related to the SI units. Coulometric titration at $\mu \mathrm{g}$ levels of urea nitrogen in serum and urine was reported by Christian et al. ${ }^{11}$ In this method, urea was enzymatically decomposed to ammonia, and it was titrated with electrogenerated hypobromite ion. On the other hand, a pretreatment method that can efficiently decompose a large quantity of urea is necessary to estimate the purity of the reference material, and it is desired that the decomposed product becomes stable in the sample solution.

The aim of the present work is to establish a simple absolute method for the determination of urea based on coulometric titration of ammonium ion produced by heating decomposition in an acid medium.

\footnotetext{
$\dagger$ To whom correspondence should be addressed.

E-mail: ttanaka@ci.kagu.tus.ac.jp
}

\section{Experimental}

Chemicals

Analytical reagent-grade chemicals were used without further purification. Water was purified on a Milli- $Q^{\circledR}$ Element System (Millipore, MA). The composition of the anolyte was $0.6 \mathrm{~mol} \mathrm{\textrm {dm } ^ { - 3 }}$ in sodium bromide and $0.05 \mathrm{~mol} \mathrm{dm}^{-3}$ in sodium tetraborate ( $\mathrm{pH}$ 8.6). The catholyte was a $1 \mathrm{~mol} \mathrm{dm}^{-3}$ potassium chloride solution. Nitrogen gas was supplied by a Type MA2-1.5 nitrogen gas separation system $(99.99 \%$ purity, Kuraray Chemical, Osaka, Japan). The molar mass of urea was $60.0556 \mathrm{~g} \mathrm{~mol}^{-1}$ and the Faraday constant was $96485.3 \mathrm{C} \mathrm{mol}^{-1}$.

\section{Apparatus}

Coulometric titration was carried out using the apparatus shown in Fig. 1. The generating current was evaluated by measuring the ohmic drop across a Type 2794 standard resistor (10 $\Omega$; Yokogawa Electric Works, Tokyo, Japan) with a Type 8508A reference multimeter (Fluke Corp., WA), with a relative standard deviation (RSD) of less than $0.002 \%$. Constant currents were supplied from a Type CCS-9 constant current source (20-150 mA; Hirama Rika Kenkyusho, Kawasaki, Japan). The time interval of the electrolysis was measured on a Model 102 electronic stop watch (Komatsu Sokuki, Tokyo, Japan) with a relative error of less than $0.001 \%$. The H-type electrolysis cell was made of Pyrex ${ }^{\circledR}$ glass, and a Teflon ${ }^{\circledR}$ silicone stopper was used as a cap. The generator anode was a platinum foil (about $113 \mathrm{~cm}^{2}$ ) and the cathode was a coiled platinum wire $(10 \mathrm{~cm} \times 1 \mathrm{~mm} \phi)$. An approximately $4 \mathrm{~cm}$ layer of $5 \%$ agar-agar gel saturated with potassium chloride was inserted as a plug in the cathode chamber. The end point of the titration was detected by the dead-stop method with an applied voltage of $150 \mathrm{mV}$ by Type-7651 controlled voltage source (Yokogawa Electric Works, Japan) between two platinum wire $(0.5 \mathrm{~cm} \times 0.5 \mathrm{~mm} \phi)$ indicator electrodes. The mass was 


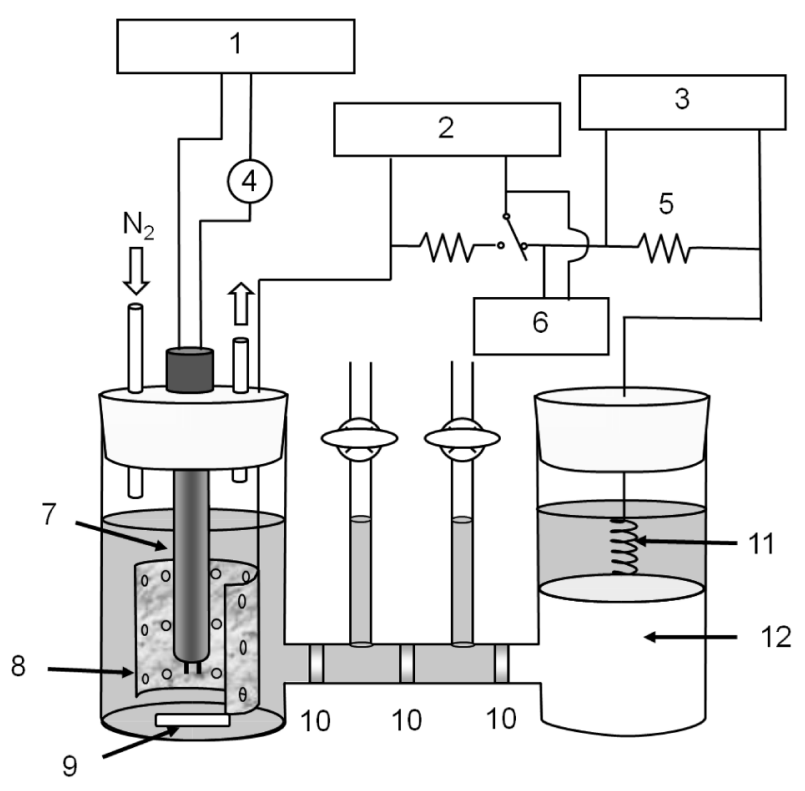

Fig. 1 Apparatus. 1, Controlled voltage source; 2, constant current source; 3 , potentiometer; 4 , microammeter; 5 , standard resistor $(10 \Omega)$; 6, timer; 7, platinum indicator electrode pair; 8, platinum anode; 9 , magnetic stirrer bar; 10, sintered-glass disk; 11, platinum cathode; 12 , agar-agar gel plug.

measured by a Type ME235S semi-micro balance (Sartorius AG, Göttingen, Germany). The agar-agar gel was changed daily, and the electrodes were washed by dipping them in $7 \mathrm{~mol} \mathrm{dm}^{-3}$ nitric acid before each run in order to keep the electrodes active.

\section{Preparation of the sample solution}

Approximately $2 \mathrm{~g}$ of sample urea, previously dried at $75^{\circ} \mathrm{C}$ for $4 \mathrm{~h}$, was accurately weighed and introduced to a $300-\mathrm{cm}^{3}$ Kjeldahl flask. Ten cubic centimeters of sulfuric acid were added to the flask. Next, an Allihn condenser was joined to the flask, and the flask was heated at around $300^{\circ} \mathrm{C}$ for $2 \mathrm{~h}$ on a mantle heater. The content of the flask was completely transferred into an accurately weighed $100 \mathrm{~cm}^{3}$ Teflon ${ }^{\circledR}$ bottle, and its volume was increased to $c a .100 \mathrm{~cm}^{3}$ with water, after cooling. The bottle was capped and exactly weighed. The mass of the content solution was determined by the difference between the mass of the filled bottle and empty bottle. The mass percent of urea was obtained by the ratio between the mass of urea and the content solution.

\section{Recommended procedure}

Approximately $140 \mathrm{~cm}^{3}$ of the anolyte was placed into an anode chamber and the solution was deaerated with nitrogen gas for about $30 \mathrm{~min}$ with vigorous stirring. Deaeration was stopped and the stirring rate was slowed, but nitrogen gas was purged to the anolyte surface throughout the entire procedure. A small quantity of ammonium ion was added to the anolyte, and pretitrated with hypobromite ion anodically generated at a constant current of $c a$. $100 \mathrm{~mA}$. Near the end point of the titration, the generating current was cut off. The indicator current was read after $1 \mathrm{~min}$. This operation was repeated every second and continued until after five seconds of the end point of the pretitration. The indicator current was measured after each charge increment. The solution in two compartments was transferred between the anode chamber and compartments several times using nitrogen gas pressure and aspiration with a syringe, and the indicator current was measured again. The end point was extrapolated from the intersection of two straight portions of the indicator current-electrolysis time curve. The accurately weighed sample solution was transferred into the anode chamber containing pretitrated anolyte directly, and the titration was carried out with the same procedure as the pretitration.

\section{Results and Discussion}

\section{Coulometric titration of ammonium ion}

Hypobromite ${ }^{12-15}$ and hydroxide ions ${ }^{14}$ have been used as a titrant for the coulometric titration of ammonia or ammonium ion. In this work, hypobromite ion was adopted as the coulometric titrant because it is generated electrolytically with $100 \%$ current efficiency in a weakly basic solution. ${ }^{16}$ Ammonium ion at milligram levels was first determined in order to evaluate the accuracy of coulometric titration with electrogenerated hypobromite ion. The analytical results of the ammonium ion standard solution (Kanto Chemical Co., Tokyo, Japan, Japan Calibration Service System (JCSS) certificated) were in fairly good agreement with the certified value $\left(1006 \mathrm{mg} \mathrm{dm}^{-3} \pm 6.04\right.$ $\mathrm{mg} \mathrm{dm}^{-3}$ ) with a relative standard deviation (RSD, $n=7$ ) of $0.30 \%$, and showed that the present method is applicable to the indirect assay of urea.

\section{Optimization of conditions for production of ammonium ion from} urea

First, the urea was directly added into the anolyte and titrated with electrogenerated hypobromite ion. However, the end point was not detected because the reaction between urea and hypobromite ion is very slow. This problem was resolved by coulometrically titrating the ammonium ion produced by the decomposition of urea.

Heating decomposition in an acid medium, microwave decomposition, and enzymatic decomposition using urease were tested as methods to produce ammonia or ammonium ion from urea. The best result of coulometric titration using the analytical reagent-grade urea, $99.83 \%$ of recovery $(n=5$ : this is the same as purity of urea), was obtained from the heating decomposition in sulfuric acid because urea is fully decomposed to ammonium sulfate upon heating as the product is stable in the acidic solution. On the other hand, recovery rates of 87.60 and $82.71 \%$ were obtained from microwave decomposition and enzymatic decomposition, respectively. As such, heating decomposition in an acid medium was adopted as the method to decompose the urea. A few mineral acids for the heating decomposition were compared. The best result, $99.77 \%$ of recovery, was gained from the sulfuric acid test. In addition, stable results of coulometric titration were obtained over 15 days. The recoveries of the test using nitric and hydrochloric acids were 96.46 and $87.60 \%$, respectively, so these two acids were considered inadequate.

Hence, urea can be decomposed at high temperatures when sulfuric acid is used. The effect of the decomposition temperature was examined at $2 \mathrm{~h}$ heating period. The purity of urea at $220^{\circ} \mathrm{C}$ was $99.785 \%$ with an $\operatorname{RSD}(n=3)$ of $2.061 \%$, at $250^{\circ} \mathrm{C}$ was $99.995 \%$ with $\operatorname{RSD}(n=3)$ of $0.429 \%$, and at $300^{\circ} \mathrm{C}$ was $99.900 \%$ with RSD $(n=3)$ of $0.008 \%$. In each case, the recovery rate was near $100 \%$, so we decided a relatively high temperature was required to decompose the urea. A low RSD was obtained at high temperatures because the urea was completely decomposed to only ammonia or ammonium ion and 


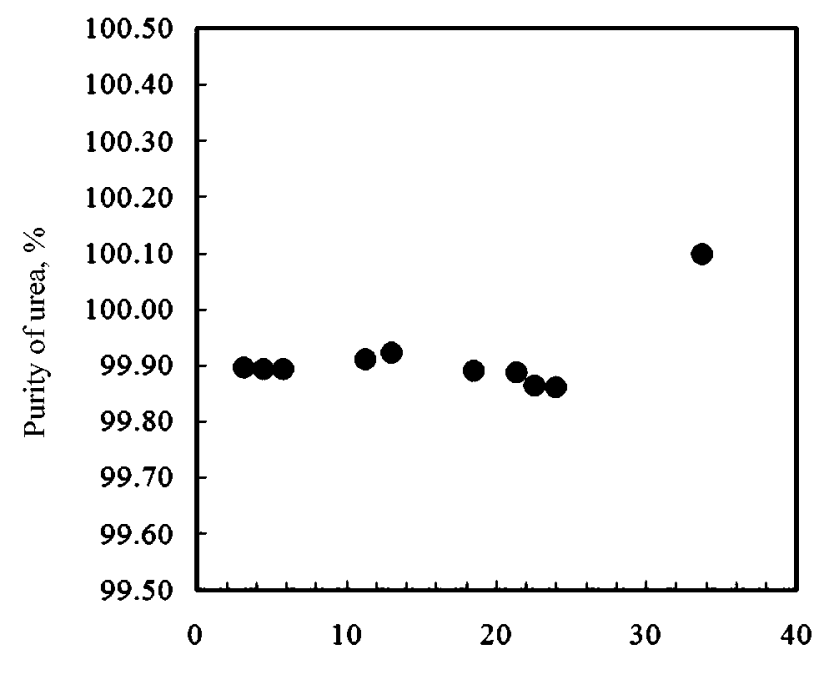

Amount of added urea / mg

Fig. 2 The relationship between the amount of added urea to the cell and the purity.

Table 1 Coulometric assay of urea

\begin{tabular}{ccc}
\hline Sample & $\begin{array}{c}\text { Assay, } \\
\%^{\mathrm{a}}\end{array}$ & $\begin{array}{c}\text { Expanded } \\
\text { uncertainty } \\
(k=2), \% \%^{\mathrm{d}}\end{array}$ \\
\hline Analytical-grade reagent $(>99.0 \%)^{\mathrm{b}}$ & 98.966 & \pm 0.190 \\
NIST SRM 912a $(99.9 \pm 0.1 \%)^{\mathrm{c}}$ & 99.870 & \pm 0.026 \\
\hline
\end{tabular}

a. Average of five determinations.

b. Purity estimated by the manufacturer (neutralization back titration). c. Certified value (differential scanning calorimetry).

d. Combined standard uncertainties are calculated from the standard uncertainty of the Faraday constant, molar mass of urea, resistance, constant-current power supply, mass of urea, and repeatability of coulometric titration.

no intermediate product remained. Therefore, $300^{\circ} \mathrm{C}$ was selected as the heating temperature.

The decomposition amount of the urea sample was considered. A recovery rate of around $99 \%$ was obtained with urea amounts up to $3 \mathrm{~g}$, but $86 \%$ at $4 \mathrm{~g}$. Therefore, we used $2 \mathrm{~g}$ of urea in $10 \mathrm{~cm}^{3}$ sulfuric acid because $3 \mathrm{~g}$ was estimated as the limit of decomposable amount.

\section{Coulometric assay of urea}

The relationship between the amount of added urea to the cell and the purity is shown in Fig. 2. The added mass of urea to the cell was calculated from the amount of ammonium ion. Satisfactory results were obtained at $3-25 \mathrm{mg}$. The end point became indefinitely beyond $30 \mathrm{mg}$, and the purity exceeded $100 \%$. When the added mass exceeded $40 \mathrm{mg}$, the end point could not be detected owing to the decrease in $\mathrm{pH}$ value of the anolyte. $^{12}$ So $20-25 \mathrm{mg}$ was selected as the added mass of urea.

The results of the coulometric assay of urea are summarized in Table 1. The assay values of the proposed method were sufficiently close to the guaranteed minimum value or certified value. The lot number of this analytical reagent-grade urea sample (Kanto Chemical Co., Japan) is different from the one used in determining the optimum conditions. The result for NIST SRM 912a urea was sufficiently precise. We thus conclude that the proposed method is effective for the absolute assay of urea.

\section{References}

1. C. Plato and A. R. Glasgow, Jr., Anal. Chem., 1969, 41, 331.

2. "Certificate of Analysis" for NIST SRM 912a, Urea.

3. JIS K 8731, "Urea", 1995, Japanese Industrial Standards Committee, Tokyo.

4. T. Tanaka, Bunseki, 1988, 474.

5. T. Tanaka, E. Shutto, T. Mizoguchi, and K. Fukushima, Anal. Sci., 2001, 17, 277.

6. T. Tanaka, A. Takahashi, S. Kobayashi, and A. Mizuike, Anal. Sci., 1993, 9, 455.

7. T. Tanaka, K. Kurooka, K. Ikeda, and T. Ogura, Nippon Kagaku Kaishi, 1998, 535.

8. T. Tanaka, H. Hayashi, Y. Komiya, H. Nabekawa, and H. Hayashi, Bunseki Kagaku, 2007, 56, 327.

9. T. Asakai and A. Hioki, Accred. Qual. Assur., 2010, 15, 391.

10. T. Asakai and A. Hioki, Microchim. J., 2013, 108, 24

11. G. D. Christian, E. C. Knoblock, and W. C. Purdy, Clin. Chem., 1965, 11, 700.

12. G. M. Arcand and E. H. Swift, Anal. Chem., 1956, 28, 440.

13. G. D. Christian, E. C. Knoblock, and W. C. Purdy, Anal. Chem., 1963, 35, 2217.

14. A. Hioki, M. Kubota, and A. Kawase, Talanta, 1991, 38, 397.

15. T. Yoshimori, M. Arai, and Y. Ikeda, J. Jpn. Inst. Met., 1967, 31, 1258.

16. E. Bishop, "Coulometric Analysis (Comprehensive Analytical Chemistry, Vol. 2D)", eds., C. L. Wilson and D. W. Wilson, 1975, Elsevier, Amsterdam, New York, 524. 